\title{
Hacia Un PluRAlismo inteligente. Respuesta a Juan Andrés Moraes
}

Towards an Intelligent Pluralism. A Reply to Juan Andrés Moraes

\author{
ADOLFO GARCÉ \\ Universidad de La República
}

\section{RESUMEN}

Es necesario aprender a debatir sin herir. Debemos ser capaces de conversar fraternalmente sobre los desafíos de la ciencia política en Uruguay. El artículo que motivó la réplica jamás pretendió ofender a nadie. Buscó verbalizar algunos de los problemas y desafíos que investigaciones recientes sobre la evolución de la ciencia política uruguaya han señalado con prudencia. No es cierto que, al invitar al pluralismo, se proponga una visión cómoda y provinciana de la ciencia política. Defender el pluralismo no implica renunciar a los estándares sino, simplemente, admitir que es posible hacer ciencia política de muchos "buenos" modos al mismo tiempo. La diversidad epistemológica, teórica y metodológica lejos de ser un problema representa una espléndida oportunidad.

Palabras clave: Ciencia política, Uruguay, pluralismo, "Movimiento Perestroika".

\begin{abstract}
We need to learn how to argue without inflicting harm. We must be able to discuss fraternally about the challenges of political science in Uruguay. The article that motivated the reply never intended to offend anyone. The article sought to verbalize some of the problems and challenges that recent research on the evolution of the Uruguayan political science have carefully noted. It is not true that our call for pluralism implies a comfortable and parochial view of political science. The defense of pluralism does not mean giving up academic standards but simply admitting that there are many "good" ways to make global political science. The epistemological, theoretical and methodological diversity far from being a problem represents a wonderful opportunity.
\end{abstract}

Key words: Political science, Uruguay, pluralism, "Perestroika Movement". 
Quiero agradecer a los editores de RCP la oportunidad de contestar el artículo en el que nuestro colega Juan Andrés Moraes hace referencia al que publicáramos en esta misma revista hace unos meses con Cecilia Rocha acerca de la evolución reciente de la ciencia política en Uruguay. RCP presta un gran servicio a la ciencia política regional al favorecer el estudio sistemático, la reflexión crítica y el debate académico acerca de la dinámica de nuestra disciplina. En nuestro caso, además, hace posible que asuntos sobre los que todavía conversamos poco y mal entre nosotros, los politólogos uruguayos, puedan debatirse más abiertamente y con otro rigor.

Confieso que la réplica de nuestro colega no me gustó. No es que discrepe, como se verá un poco más adelante, con la totalidad del contenido de su respuesta. Si se mira a fondo, estamos de acuerdo en asuntos fundamentales. Pero encuentro que su texto está más orientado al golpe de efecto que a proponer una buena discusión. En primer término, Moraes no hace ningún esfuerzo por preguntarse si no tendremos algo de razón al sostener que la ciencia política uruguaya se caracteriza por un pluralismo "incómodo". En segundo lugar, nos hace sostener puntos de vista que nunca defendimos. En concreto, afirma que los autores del artículo que mereció su réplica renunciamos a los estándares de exigencia globales. De ninguna manera. Queda claro en nuestro texto, y también subrayo ahora, que aspiramos también nosotros a una ciencia política exigente.

De todos modos, en un sentido muy preciso su réplica me resulta útil. Por forma y fondo ayuda a echar luz sobre las raíces de la "incomodidad" a la que hacemos referencia en el artículo. Me parece un buen ejemplo de discusión mal dada y de cómo se puede incomodar a los demás simplemente con palabras. Su texto tiene dos argumentos centrales. El primero de ellos busca rebatir nuestro diagnóstico acerca de las restricciones que padecería el pluralismo (epistemológico, teórico y metodológico) en Uruguay. Más específicamente, afirma que son los pluralistas (y no los que él denomina "incomodadores") quienes "gobiernan" la ciencia política uruguaya. El segundo es que el pluralismo (el que defendemos Rocha y yo) es "cómodo" y perezoso: no tiene estándares de excelencia. Pero antes de volver sobre estos dos argumentos, quiero dedicar unos renglones a las "reglas de juego" del debate entre colegas.

\section{I. ¿INCOMODADORES?}

Lamento que Moraes haya inventado la etiqueta de "incomodadores". Lo lamento porque complica los términos de la discusión, en la medida en que la traslada desde el plano general en el que nosotros la colocamos a un terreno más personal. Para poder conversar amistosa y constructivamente sobre acuerdos y desacuerdos hay que evitar personalizar. Tenemos que discutir sobre ideas y no sobre personas. Es evidente que siempre que se olvida esa regla el reencuentro se vuelve más difícil.

"Lo cortés no quita lo valiente" dice el refrán con todo acierto. En nuestro caso, esta manera de discutir es una norma de conducta general. Pero tratándose de un debate entre compañeros de trabajo hemos sido especialmente cautelosos. Dice nuestro texto cuando pasa a ocuparse de la espinosa discusión acerca del pluralismo: "Por tanto, desde el punto 
de vista de sus prácticas, esto es, de lo que efectivamente 'hacen' los politólogos cuando investigan, se podría afirmar que la ciencia política uruguaya sigue siendo pluralista: sigue habiendo margen para que las personas hagan distintas cosas. Pero se trata de un pluralismo incómodo, vergonzante, asediado. Es difícil definir la situación con precisión y sin cometer injusticias. Una forma que pretende ser constructiva y elegante de hacerlo es la siguiente: puede decirse que el pluralismo real (...), el que persiste tesonero en el terreno de las prácticas, convive con un discurso que lo invalida y constriñe. En Uruguay, como en la academia norteamericana especialmente antes del 'Movimiento Perestroika', se ha vuelto especialmente potente en términos discursivos una forma específica de entender qué es hacer 'buena' ciencia política (o ciencia política 'propiamente dicha')".

No hablamos de personas. Nunca individualizamos. Asumimos que es "difícil definir la situación con precisión". No queremos "cometer injusticias". Buscamos una forma "constructiva y elegante" de plantear un problema delicado. Juan Andrés me conoce bien. Sabe que cuido mis palabras. Mucho me temo que él no haya tomado las mismas precauciones que yo al incursionar en este debate. Leyendo su texto, tengo la impresión que polemiza con personas que no conoce, o que viven a decenas de miles de kilómetros de distancia. Sin embargo, nos conocemos desde nuestros tiempos de estudiantes, hace cerca de 25 años. Hemos tenido siempre, y espero que sigamos teniendo, un trato excelente. Nos vemos todos los días en el ICP. Trabajamos en escritorios contiguos. No estoy dispuesto a que la delgada pared de yeso que separa nuestros boxes se convierta en la Muralla China.

\section{II. ¿WHO GOVERNS?}

Moraes tiene razón en un punto importante. Los colegas que él (y no nosotros) denomina "incomodadores" no controlan los resortes de poder de la disciplina. En verdad, ninguna minoría domina la ciencia política uruguaya. Así de pluralista es Uruguay, en general, y la Universidad de la República, en particular. Nunca hay dominaciones incontestadas. Como en New Haven cuando Robert Dahl se ocupó de ella, el poder está fragmentado, disperso. El nuestro es un típico escenario pluralista, en el que muchas minorías disputan recursos e influencia. Sin embargo, como el propio Dahl explicara, el pluralismo tiene sus bemoles. Suele ocurrir que algunas minorías terminan siendo más influyentes que otras. Por cierto, no hace falta leer los Dilemas del pluralismo democrático para aceptar que una minoría puede dominar a otras. Tampoco es necesario leer a Foucault o a Marx. Esta noción es tan vieja como la teoría política misma y sigue tan vigente ahora como hace dos mil quinientos años. Moraes deberá concederme que si una minoría puede lo más (dominar a la mayoría), también debe poder lo menos (incomodarla). Desde luego, para dominar se requieren más recursos que para incomodar. En concreto, para dominar en la ciencia política hay que ocupar los cargos que permiten controlar, por ejemplo, mecanismos de reclutamiento y canales de publicación. Para incomodar, en cambio, se precisa mucho menos que eso. No hacen falta cargos. Alcanza y sobra con palabras. 
Nadie monopoliza cargos. Nadie ejerce un control hegemónico de los recursos de poder. Pero, circula, eso sí, un discurso que establece jerarquías, que aprueba y desaprueba midiendo a los demás con su propia vara. Circula, incomodando, un discurso que constriñe el pluralismo. Moraes escribió que esta afirmación es "prejuiciosa" y que carece de "sustento empírico". No está bien informado. Durante los últimos años se llevaron adelante dos investigaciones importantes sobre cómo se hace ciencia política en Uruguay. Cecilia Rocha, para obtener el título de Licenciada en Ciencia Política, realizó una investigación excelente, tanto por la profundidad de la discusión teórica como por la evidencia construida. ${ }^{1}$ Luego, sobre la base de esta investigación publicó un artículo en la Revista Uruguaya de Ciencia Política que, como corresponde, fue sometido a una evaluación rigurosa. En él puede leerse el siguiente pasaje (las cursivas me corresponden): "En las entrevistas realizadas se identificó que estarían conviviendo dos concepciones (...) distintas sobre lo que la ciencia política debería ser. Por un lado, están quienes plantean que se debe seguir 'el modelo de la economía' que fue la ciencia social que ha logrado acercarse al modelo de las ciencias naturales (...). Y por otro lado, están quienes cuestionan lo que perciben como una creciente 'hegemonía excluyente' de estas visiones, y consideran que la ciencia política se enriquece en la medida en que se mantiene su comprensión como una ciencia en sentido amplio (...) que existió desde el inicio del proceso de institucionalización de la disciplina en el país. Una noción que habilita 'muchas formas de hacer ciencia política', desde este punto de vista, es fundamental para dar cuenta de la complejidad creciente del mundo político (Gibbons, 2006)". (Rocha Carpiuc, 2012: 118). Paulo Ravecca, a su vez, en el contexto de la elaboración de su tesis de doctorado, ${ }^{2}$ también ha investigado a fondo sobre la evolución reciente de la ciencia política. Y llegó a una conclusión similar a la reportada por Rocha. En uno de los textos que ha elaborado dice: "Lo que se detecta en el ICP es una suerte de confusión discursiva, donde una minoría asertiva y segura de sí afirma una cierta manera de entender la práctica científica que es simple, concreta y clara frente a una mayoría que no tiene un libreto articulado y propio y que parece colocarse en posición defensiva, retrocediendo a regañadientes" (Ravecca, 2014: 44).

Tanto Rocha como Ravecca, por tanto, identifican tensiones significativas en la comunidad politológica uruguaya. Nuestro artículo, cuando se refiere a los constreñimientos del pluralismo, se apoya en esa acumulación. Insisto: Rocha y Ravecca, para sus respectivas tesis, diseñaron y ejecutaron investigaciones cabales. En particular, recogieron numerosos testimonios mediante entrevistas a colegas. Desde luego, Moraes puede pensar que las conclusiones de esos trabajos son erróneas. Como es de orden en el ámbito científico nada le impide llevar adelante una investigación similar para, llegado el caso, falsar las conclusiones que considera equivocadas. Lo invito fraternalmente a que lo haga. Él

1 Rocha Carpiuc, Cecilia. 2012. “El desarrollo de la Ciencia Política en Uruguay (1989-2009): Temas, teorías y metodologías". Licenciatura en Ciencia Política, ICP-FCS-UDELAR. Monografía final. Se la puede solicitar a la autora al email siguiente: cecilia.rocha@cienciassociales.edu.uy

2 Ravecca, Paulo. Political Science and the politics of science: a reflection from the Latin American experience. Tesis de Doctorado, Departamento de Ciencia Política, York University (Toronto, Canadá). Bajo la dirección del Prof. David McNally. 
afirma que nuestras aseveraciones son prejuiciosas. Estoy completamente de acuerdo con él en que nadie debería hacer afirmaciones sin fundamento. Nadie. Ni nosotros ni él. Por eso pregunto: ¿cuál es la evidencia empírica de las suyas?

\section{PLURALISMO, ESTÁNDARES Y PERESTROIKA}

Moraes afirma que quienes defendemos una visión pluralista de la ciencia política renunciamos a los estándares. Dice: "Como una oda al parroquialismo, el pluralismo uruguayo reivindica su propia ciencia política: una ciencia política autóctona". Esta frase me deja perplejo.

Muy por el contrario, en el artículo que mereció su réplica queda muy claro que nosotros también aspiramos a una ciencia política con estándares exigentes. Por ejemplo, en la sección sobre "desafíos y debates" puede leerse: "(...) la ciencia política uruguaya debe 'internacionalizarse'. Como se dijo en la sección anterior, sigue siendo bajo el número de artículos publicados por politólogos uruguayos en las revistas académicas más prestigiosas, especialmente en las editadas en inglés". En el pasaje referido habíamos escrito lo siguiente: "Desde nuestro punto de vista es positivo (tanto para la disciplina como para el sistema político y la ciudadanía) que los politólogos sigan siendo escuchados en Uruguay. Sin embargo, dada la internacionalización de los procesos de construcción de las ciencias, es igualmente necesario que los cientistas políticos que trabajan en Uruguay sean leídos por sus colegas en otras partes. La información disponible sugiere que esto todavía ocurre muy poco. El estudio de Altman (2011) sobre la productividad de los departamentos de ciencia política latinoamericanos muestra un panorama preocupante para el ICP (FCS-UdelaR) que, como ya se dijo, sigue siendo el principal epicentro de la producción politológica en el país. Su análisis, que se basa en la presencia en el Social Sciences Citation Index and the Arts \& Humanities Citation Index, ambas bases del ISI-Web of Knowledge (WoK), coloca al ICP en el lugar 19 de un ranking de 21 centros estudiados". Si nos hacemos eco de este trabajo de Altman es, precisamente, porque nos preocupan tanto la productividad como el impacto. Aspiramos a más.

¿De dónde infiere nuestro compañero de trabajo que el pluralismo, al menos en los términos en los que lo formulamos en el artículo que mereció su réplica, no procura estándares? Queremos, como Moraes, que mejore la calidad de nuestra producción y que aumente su impacto internacional. No tengo ningún problema en dejar por escrito, aquí, lo que vengo diciendo en privado: me inclino a pensar que nuestro ICP deberá seguir revisando su política de incentivos. En esto seguramente coincidimos con Moraes. Sospecho, de todos modos, que tenemos diferencias importantes respecto de qué revistas cabe considerar "científicas". Por ejemplo, él afirma que la única forma de ciencia es la que sigue el enfoque positivista. Dice textualmente: "Los incomodadores uruguayos son positivistas, porque no se puede esperar otra cosa de un profesional de una disciplina que tiene a la palabra ciencia en su propio nombre". Esto sí que es un prejuicio. En lo personal, no tengo ningún problema con el positivismo. De hecho, inscribo mi propio trabajo en el neopositivismo. Pero considero un error grave no 
asignarle estatus científico a los enfoques que rechazan la epistemología positivista (críticos, posmodernos, interpretativistas, etcétera). Los enfoques no positivistas forman parte de la ciencia política. El Nuevo Manual de Ciencia Política de Goodin y Klingemann, para no ir más lejos, los incluye entre las "nuevas voces" de la disciplina: "Entre las nuevas voces claramente representadas hoy en la ciencia política, en comparación con hace un cuarto de siglo, destacan las de los posmodernos y las feministas" (2001: 47). Moraes tiene todo el derecho del mundo de identificarse con el positivismo. No debería, en cambio, deslegitimar a quienes no comulgan con esta visión de la producción de conocimiento. Y si lo hace debería aceptar que un discurso de este tipo resulte "incómodo" para los implicados. Pero sospecho que tendríamos otra discrepancia importante. Sigo pensando que, sin perjuicio de tratar de publicar más y mejor en inglés y en revistas del Norte, hay que seguir escribiendo y publicando artículos y libros en español, en Uruguay y la región. Soy de los que piensa que los cientistas sociales, especialmente los que trabajamos en universidades financiadas con fondos públicos, tenemos una obligación cívica muy especial. Además de intentar contribuir al progreso general de nuestra disciplina, tenemos que intentar aportar a la resolución de los problemas de nuestro entorno inmediato. Una nueva política de incentivos, desde mi punto de vista, debería tener estos dos grandes objetivos en consideración al mismo tiempo. No es sencillo, pero es posible y necesario.

Para terminar me quiero referir brevemente a la analogía con el "movimiento Perestroika" que propusimos en nuestro artículo. Es evidente que entre la ciencia política de EE.UU. en tiempos del "movimiento Perestroika" y las tensiones actuales dentro de la ciencia política uruguaya hay diferencias importantes. Pero llama la atención que justamente Moraes, que rechaza sistemáticamente el parroquialismo, nos critique por intentar colocar las tensiones de la disciplina en Uruguay en un marco más general. La analogía, a pesar de las obvias diferencias, funciona bien. En ambos lados, en el fondo del debate, late la cuestión del pluralismo (epistemológico, teórico y metodológico). Dicho sea de paso, es evidente que esta tensión también se ha manifestado en otras academias de la región, como puede verse recorriendo el volumen de RCP publicado hace ya diez años. Fernández, por ejemplo, reporta que en Chile existe un "debate latente": "no solo en lo que respecta a la hegemonía americana de la ciencia política, sino a las aspiraciones de unilateralidad de sus enfoque predominantes" (2005: 67). Loaeza, estudiando el desarrollo de la ciencia política mexicana, también reporta una tensión entre "escuelas": "en México se reproduce el mismo debate que se desarrolla (...) a nivel internacional, entre quienes creen que los estudios históricos y descriptivos deberían ser desplazados por 'investigaciones fundadas en teóricas comprensivas de alto rigor analítico y metodológico' (Negretto, 2004: 183) como si la explicación histórica careciera de profundidad analítica" (2005: 201-202). ${ }^{3}$ Amorim Neto y Santos argumentan que en Brasil existen "dos escuelas que no se comunican entre sí, una empírica y otra normativo-filosófica" y lamentan la disolución de esa "alianza victoriosa" fundacional (2005: 101-102). Leiras, Abal Medina

3 Rivera y Salazar-Elena (2011:74) señalan que el debate se está dando en la comunidad politológica pero en "los pasillos y aulas de los centros de investigación". 
y D'Alessandro muestran que la ciencia política en Argentina ofrece "un panorama de 'mesas separadas' como el que preocupaba a Almond": "Con los estudios más cercanos al mainstream norteamericano coexiste un firme interés y una lectura informada de los autores clásicos de la tradición política occidental" (2005: 81). Como suele ocurrir, cada caso es distinto. Pero tensiones entre escuelas y corrientes no hay solamente en Uruguay. El pluralismo sobrevive, pero no siempre lo hace sin penar.

\section{HACIA UN PLURALISMO INTELIGENTE}

Quiero terminar rescatando algunas coincidencias relevantes e invitando a construir otras formas de discusión. En primer lugar, Moraes dice en una escueta nota al pie que lo que él rechaza en verdad es el pluralismo convertido en laissez-faire: "en cierto modo todos compartimos el ADN y la filosofía del pluralista". Celebro esta definición. Me parece que ofrece un punto de encuentro muy importante. Desde luego habrá que discutir qué alcance tiene concretamente el matiz "en cierto modo" con el que inicia su frase. Por lo que dijo en otra parte de su texto (al referirse al positivismo), parece que su "modo" de inscribirse en el pluralismo es diferente al mío. En segundo lugar, en su réplica insiste mucho en la cuestión de los estándares. Completamente de acuerdo en aspirar a la excelencia y en promoverla sistemáticamente. También estoy de acuerdo en seguir buscando formar parte de las mejores redes académicas. Finalmente, me parece muy importante que publiquemos más y mejor en inglés. En este sentido, valoro muy especialmente el esfuerzo de Juan Andrés Moraes por publicar en las revistas más prestigiosas de nuestra disciplina. Recorre un camino de esfuerzo y excelencia que muchos otros colegas de nuestro ICP, aunque él no lo advierta, con sus propios ritmos, también se empecinan en transitar.

Más allá de coincidencias, tenemos y seguiremos teniendo profundas diferencias en cuanto a cómo concebimos la ciencia política. No hay, en este sentido, de qué sorprenderse o alarmarse. Hubo, hay y ojalá siga habiendo, entre otras corrientes en pugna, positivistas e interpretativistas, marxistas y liberales, "materialistas" e "idealistas". Debemos decidir cómo afrontar esta tendencia a la fragmentación (inherente a la expansión) que vuelve a nuestra disciplina más y más diversa. El pluralismo, mirado desde este punto de vista, es inexorable. Pero debemos preguntarnos qué tipo de pluralismo vamos a construir. Debemos optar. Tenemos que elegir entre un pluralismo vacío, de baja calidad, de sospechas y recelos mutuos, de "mesas separadas" y sectas al acecho (Almond, 1988) o un pluralismo crítico, inteligente, dialogante, abierto a las razones y argumentos de los otros. Tenemos que elegir entre leernos o ignorarnos. Debemos decidir entre agraviarnos o ayudarnos. El camino del pluralismo crítico, el de la "fricción" inteligente entre paradigmas epistemológicos, teóricos y metodológicos diferentes es el más difícil de transitar pero el que a la larga dará mejores frutos. Espero contar con la vocación por la excelencia y la buena voluntad de Juan Andrés Moraes en la construcción de ese clima constructivo de discusión a la vez fraterno y exigente que tanta falta nos hace. 


\section{REFERENCIAS}

Almond, Gabriel. 1988. "Separate Tables: Schools and Sects in Political Science". Political Science 21 (4): 828-842.

Amorim Neto, Octavio y Fabiano Santos. 2005. "La ciencia política en Brasil: el desafío de la expansión". Revista de Ciencia Política 25 (1): 101-110.

Fernández, María de los Ángeles. 2005. "Ciencia política en Chile: un espejo intelectual”. Revista de Ciencia Política 25 (1): 56-75.

Goodin, Robert y Hans-Dieter Klingemann. 1996. "Ciencia política: la disciplina", en Goodin, Robert y Hans-Dieter Klingemann (eds.), Nuevo manual de Ciencia Política, t. I., Istmo: Madrid, pp. 21-82.

Leiras, Marcelo; Juan Abal Medina (H.) y Martín D'Alessandro. 2005. “La ciencia política en Argentina: el camino de la institucionalización dentro y fuera de las aulas universitarias". Revista de Ciencia Política 25 (1): 76-91.

Loaeza, Soledad. 2005. "La ciencia política: el pulso del cambio mexicano". Revista de Ciencia Política 25 (1): 192-203.

Ravecca, Paulo. 2014. "La política de la ciencia política en Chile y Uruguay: ciencia, poder y contexto. Documento on line $\mathrm{N}^{\mathrm{o}} 1 / 14$. Instituto de Ciencia Política, FCS-UDELAR. Montevideo.

Rivera, Mauricio y Rodrigo Salazar-Elena. 2011. “El estado de la ciencia política en México. Un retrato empírico". Política y Gobierno XVIII (1): 73-108.

Rocha Carpiuc, Cecilia. 2012. “La Ciencia Política en Uruguay (1989-2009): Temas, teorías y metodologías”. Revista Uruguaya de Ciencia Política 21 (1): 97-127.

Topper, Keith. 2005. The Disorder of Political Inquiry. Cambridge - London: Harvard University Press.

Adolfó Garcé es Doctor en Ciencia Política (Universidad de la República). Sus campos de investigaciones centrales son la dinámica de las ideologías políticas y el poder político de las ideas. Es autor de una decena de libros como autor, coautor o coordinador, y publicó una veintena de artículos en revistas científicas. Se desempeñó como Presidente de la Asociación Uruguaya de Ciencia Política (20142015). Es uno de los fundadores del Grupo de Investigación de ALACIP “Ideas, Discursos y Política”. E-mail: adolfogarce@gmail.com 